\title{
PRODUÇÃO DE ETANOL VIA FERMENTAÇÃO COM RECICLO DE CÉLULAS: CINÉTICA USANDO REDES NEURAIS ARTIFICIAIS
}

\author{
L. A. P. SOARES, R. R. ANDRADE, T. D. MARTINS
}

\begin{abstract}
Universidade Federal de São Paulo, Departamento de Ciências Exatas e da Terra
E-mail para contato: lucas_adriel1@ @otmail.com; tdmartins@unifesp.br
\end{abstract}

\begin{abstract}
RESUMO - O reciclo de células, uma realidade da indústria brasileira de produção de etanol, pode ser potencialmente utilizando para a segunda geração. O intuito desse modo de operação é reduzir os custos e o tempo de fermentação. Desse modo, é importante se desenvolver um modelo cinético que seja bastante preciso. As Redes Neurais Artificiais (RNAs) tem uma grande capacidade de auxiliar na busca desse modelo. Neste trabalho, foram utilizadas RNAs para se modelar os dados da fermentação alcóolica do hidrolisado de bagaço de cana-de-açúcar concentrado com melaço, à temperatura de $34^{\circ} \mathrm{C}$, e 7 reciclos de células. Como variáveis de entrada, foram utilizados valores da concentração de substrato, células e etanol no tempo $t \mathrm{e} t-1 \mathrm{e}$ como variáveis de saída as concentrações de substrato, células e etanol no tempo $t+1$. Os resultados mostraram que uma única RNA tem a capacidade de aprender e simular satisfatoriamente o processo com reciclo.
\end{abstract}

\section{INTRODUÇÃO}

Existem muitos estudos que tem como foco a utilização de biomassa para a produção de energia, por ser uma forma renovável de matéria prima. A fermentação alcóolica do hidrolisado de bagaço de cana-de-açúcar, concentrado com melaço, com reciclo de células é um desses processos. Isso porque, além da cana-de-açúcar ser uma fonte de energia renovável, a utilização do reciclo de células faz com que o processo seja mais rápido e tenha custos menores.

Apesar disso, até onde se sabe, há apenas dois estudos que abordaram a modelagem da cinética da fermentação de etanol de segunda geração, considerando reciclo de células (Andrade et al., 2013 e Guerra et al., 2015). As RNAs aparecem como uma alternativa à modelagem convencional, pois tem a capacidade de generalização e também oferece flexibilidade para se adaptar a situações completamente diferentes (Fonseca et al., 2000).

Sua formação é composta por neurônios artificiais que tem por base o funcionamento do neurônio biológico. A estrutura de uma RNA é formada por uma camada de entrada, uma camada de saída e camadas ocultas, conforme a Figura 1. Pesos sinápticos estão presentes em cada neurônio e são associados aos estímulos advindos da camada anterior através da função soma. É possível ajustar o número de neurônios em cada camada e a determinação dos pesos sinápticos constitui a obtenção do modelo neural. 
Figura 1 - Estrutura de um RNA. FONTE: Ramos (2003)

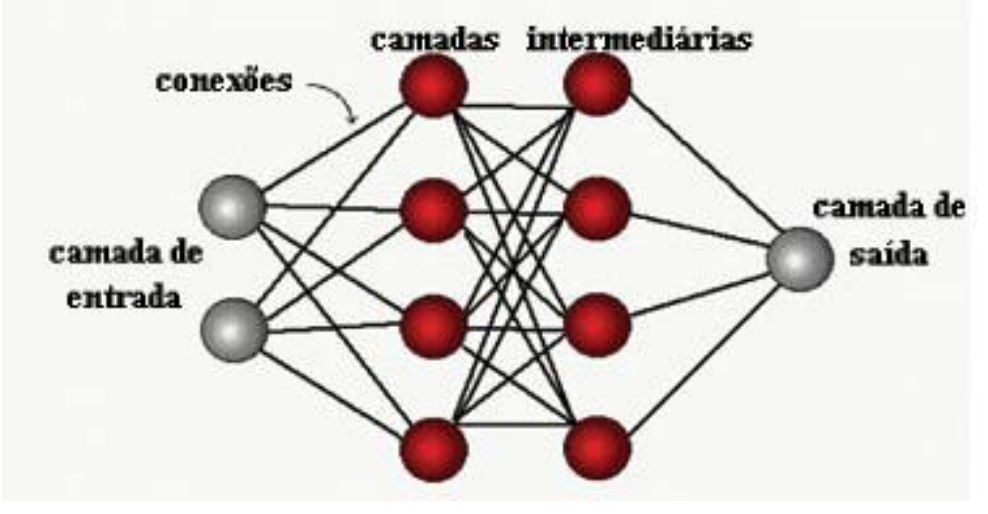

O principal objetivo desde trabalho é obter um única RNA que seja capaz de modelar cineticamente a fermentação alcóolica do hidrolisado de bagaço de cana-de-açúcar, concentrado com melaço, à temperatura de $34^{\circ} \mathrm{C}$, considerando 7 reciclos de células. Além disso, espera-se obter um modelo capaz de simular ciclos independentes, que não foram apresentados na etapa de treinamento.

\section{MATERIAIS E MÉTODOS}

\subsection{Obtenção dos Dados Experimentais}

A partir de Andrade (2012), foram obtidos os dados experimentais utilizados neste trabalho. Em seu trabalho, ele utilizou o hidrolisado do bagaço da cana-de-açúcar, concentrado com melaço, como matéria-prima para a fermentação. A Tabela 1 apresenta o tempo de fermentação para cada ciclo realizado.

Tabela 1 -Tempo de fermentação para cada ciclo

\begin{tabular}{cc}
\hline Ciclo & Tempo de fermentação $(\mathrm{h})$ \\
\hline 1 & 30,45 \\
2 & 36,77 \\
3 & 39,58 \\
4 & 36,03 \\
5 & 44,55 \\
6 & 45,45 \\
7 & 37,67 \\
\hline
\end{tabular}

\subsection{Tratamento dos Dados de Entrada e Saída}

O número de dados coletados no trabalho de Andrade (2012) é limitado para se treinar uma RNA, portanto foi necessário gerar uma maior quantidade de pontos para o treinamento. O programa Table Curve 2D foi utilizado para essa geração, sendo que curvas sigmoidais foram ajustadas aos dados de concentração de células $(X)$, de substrato $(S)$ e de etanol $(P)$. 
Foram gerados 100 pontos para cada experimento, que é um número aceitável para o treinamento e validação do modelo.

\subsection{Simulações}

O aprendizado das RNAs é o que faz com que elas sejam uma alternativa às limitações da modelagem fenomenológica. A aprendizagem ocorre devido às mudanças nos pesos sinápticos, que empregam um algoritmo de otimização a fim de minimizar uma função objetivo. A seguinte função objetivo foi minimizada para se obter os pesos sinápticos da rede:

$$
F_{o b j}=\sum_{i=1}^{m} \frac{\left(y-y^{\prime}\right)^{2}}{m}
$$

em que: $y$ é o valor estimado pela rede, $y^{\prime}$ é o valor real fornecido à rede e $m$ é o número de dados experimentais fornecidos à rede.

A estrutura geral de rede selecionada foi: uma camada oculta, tangente sigmoidal como função de ativação em todas as camadas e número de neurônios na camada intermediária variando entre 3 e 10.

Houve a necessidade de se utilizar uma estratégia para embutir o parâmetro temporal no ajuste do modelo, já que as RNAs da forma que foram concebidas possuem capacidade para tratar de dados em equilíbrio. Para isso, os parâmetros utilizados como variáveis de entrada foram: as concentrações de substrato, células e etanol no tempo $t$ e $t-1$. As variáveis de saída escolhidas para serem obtidas foram as concentrações de substrato, células e etanol no tempo $t+1$. Os dados foram divididos entre treinamento, validação e teste, sendo que a porcentagem para cada um foi de $70 \%, 15 \%$ e $15 \%$, respectivamente. O perfil cinético de 5 ciclos foram apresentados na etapa de treinamento e o método de otimização escolhido foi o Resilient Backpropagation.

Uma vez as RNAs treinadas, realizou-se a simulação com a RNA que apresentou os melhores resultados, na tentativa de simular os dois ciclos que foram omitidos na etapa anterior. Por fim, os resultados que foram gerados pela RNA foram comparados com os experimentais coletados para os determinados ciclos. Na Tabela 2 são apresentados os valores utilizados na entrada das RNAs para o treinamento e para simulação.

Tabela 1 - Parâmetros de entrada da rede para o treinamento e simulação

\begin{tabular}{ccccc}
\hline Ciclo & Utilização & Células $(\mathrm{g} / \mathrm{L})$ & Substrato $(\mathrm{g} / \mathrm{L})$ & Etanol $(\mathrm{g} / \mathrm{L})$ \\
\hline 1 & Treinamento & $2,69-6,39$ & $150,628-0$ & $2,436-72,495$ \\
2 & Treinamento & $5,91-10,66$ & $133,737-0$ & $20,796-83,799$ \\
3 & Treinamento & $6,43-12,09$ & $143,263-0$ & $23,952-80,838$ \\
4 & Simulação & $7,98-13,84$ & $140,553-0$ & $22,512-84,255$ \\
5 & Treinamento & $9,46-15,48$ & $148,604-0$ & $23,520-88,479$ \\
6 & Simulação & $8,50-14,66$ & $140,294-0$ & $25,068-86,964$ \\
7 & Treinamento & $5,91-10,12$ & $143,436-0$ & $22,860-85,788$ \\
\hline
\end{tabular}




\section{RESULTADOS E DISCUSSÃO}

Diferentes estruturas de RNAs foram utilizadas para realizar a modelagem. Na Tabela 3 são apresentados os valores de função objetivo e $r^{2}$ para cada uma das estruturas testadas para a modelagem.

Tabela 3 - Valores de função objetivo e $r^{2}$ para as diferentes estruturas das redes

\begin{tabular}{cccc}
\hline Estrutura & Função objetivo & $r^{2}$ Treino & $r^{2}$ Validação \\
\hline $6-3-3$ & 8,40 & 0,997 & 0,996 \\
$6-5-3$ & 0,92 & 0,999 & 0,999 \\
$6-7-3$ & 0,31 & 0,999 & 0,999 \\
$\mathbf{6 - 1 0 - 3}$ & $\mathbf{0 , 0 7}$ & $\mathbf{0 , 9 9 9}$ & $\mathbf{0 , 9 9 9}$ \\
\hline
\end{tabular}

Ao se analisar a Tabela 3, foi possível observar que todas as redes obtiveram um valor satisfatório para o $r^{2}$. Entretanto, a rede com 10 neurônios na camada intermediária se mostrou a melhor, já que foi a que resultou em menor valor da função objetivo. Portanto, a estrutura 7-10-3 foi a escolhida para se realizar a simulação.

A Figura 2 apresenta a relação entre os valores experimentais e do treinamento para as variáveis: concentração de substrato, células e etanol para a estrutura 6-10-3. É possível se visualizar nessa Figura a excelente correlação entre os valores preditos pela RNA e os experimentais, já que praticamente todos os pontos estão sobre a reta de $45^{\circ}$.

Figura 2 - Valores preditos versus experimentais obtidos na etapa de treinamento

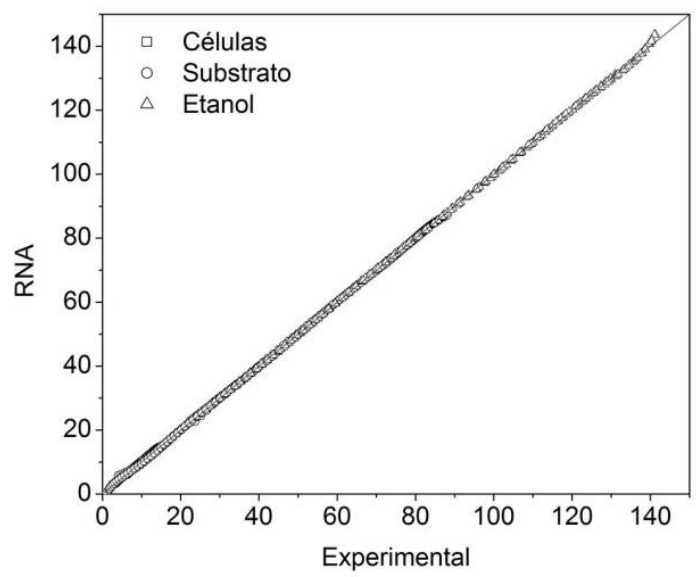

Para a simulação da RNA treinada, foram utilizados valores das variáveis de entrada que não foram usados no treinamento da rede, de acordo com a Tabela 2. As RNAs não possuem capacidade de extrapolação, portanto os valores utilizados precisam estar dentro da faixa dos que foram apresentados no treinamento. Nas Figuras 3 e 4 são mostrados os valores experimentais (símbolos fechados) e simulados pela RNA (símbolos abertos), para os ciclos 4 e 6. 


\section{Congresso Brasileiro de Engenharia Química em Iniciação Científica UFSCar - São Carlos - SP 16 a 19 de Julho de 2017}

Figura 3 - Valores experimentais e simulados pela RNA para o ciclo 4.

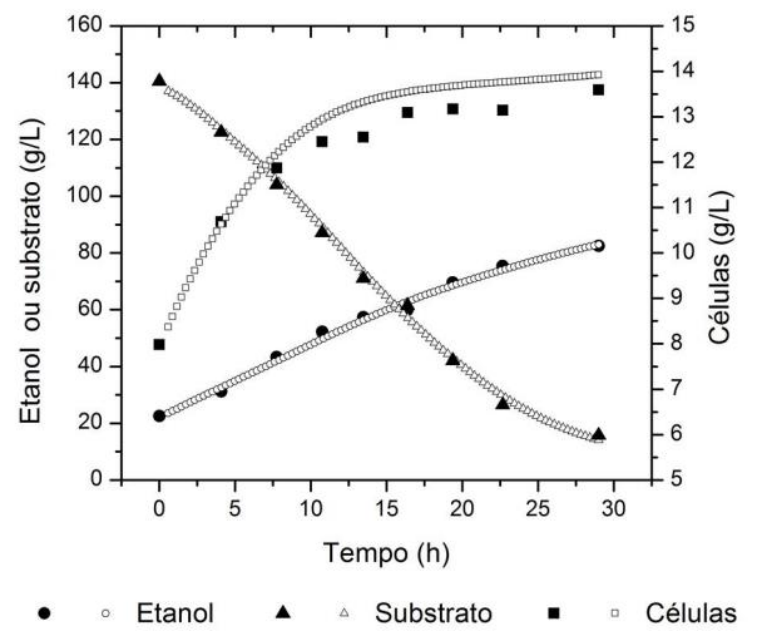

Figura 4 - Valores experimentais e simulados pela RNA para o ciclo 6.

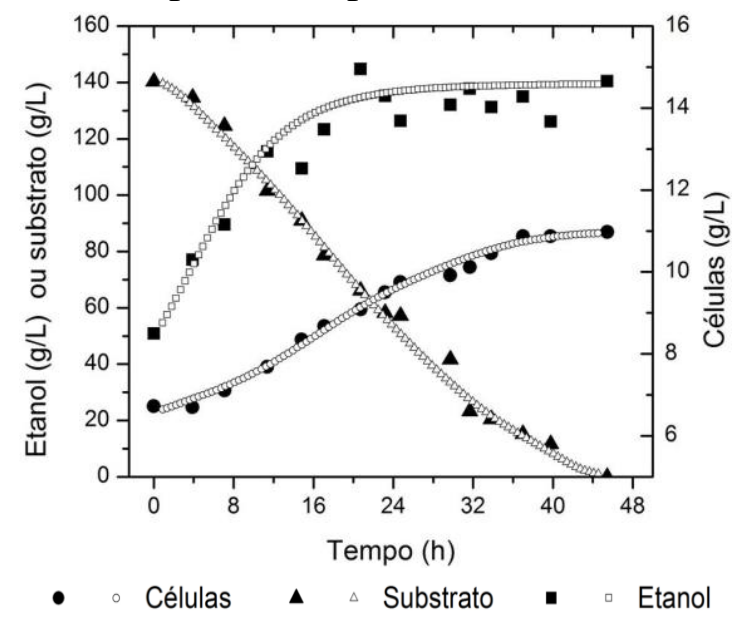

Nas Figuras 3 e 4, é possível assegurar que a RNA tem a capacidade de simular satisfatoriamente a cinética de fermentação de dois reciclos de um processo de fermentação alcóolica, pois os valores simulados acompanharam o comportamento dos dados experimentais.

Além disso, foi possível predizer os dados dos reciclos sem a necessidade de se utilizar a variável concentração de ácido acético, ou ter conhecimento mais profundo do comportamento da cinética de crescimento e de produção em processos com reciclo, o que dificultava o ajuste do modelo fenomenológico no trabalho de Andrade (2012).

Este trabalho apresentou que para uma RNA os valores de entrada de $X, S$ e $P$ são suficientes para a descrição da cinética de fermentação para todos os reciclos. Acrescenta-se a isso, a sua simplicidade e facilidade computacional, já que uma vez treinada a rede, esta não requer métodos de integração para sua resolução.

O uso das redes neurais como uma alternativa aos modelos fenomenológicos se torna interessante devido a sua generalização, simplicidade e praticidade. Além disso, a utilização do reciclo celular pode impactar na cinética do processo, o que dificulta o procedimento de reestimação de parâmetros. Isso é uma nova dificuldade quando se trabalha com os modelos fenomenológicos, pois os parâmetros necessitam ter um significado físico. Ou seja, esse fato confirma como as redes podem facilitar o trabalho de se modelar o processo.

\section{CONCLUSÃO}

Neste trabalho, foram empregadas RNAs para se modelar a cinética de fermentação alcóolica com reciclo de células. As variáveis de interesse foram as concentrações de substrato, de células e de etanol no tempo $t+1$. Os resultados dos treinamentos demonstraram que a rede com 10 neurônios na camada intermediária consegue reproduzir satisfatoriamente o processo. Além disso, ao se simular processos de fermentação que não foram apresentados no treinamento, os resultados confirmaram o poder de generalização dessa ferramenta. 


\section{AGRADECIMENTOS}

Agradecemos ao CNPq pelo suporte financeiro ao desenvolvimento desse trabalho.

\section{REFERÊNCIAS}

ANDRADE, R.R., MAUGERI FILHO, F.; MACIEL FILHO, R.; DA COSTA, A.C. Kinetics of ethanol production from sugarcane bagasse enzymatic hydrolysate concentrated with molasses under cell recycle, Bioresource Technology, v. 130, p. 351-359, 2013.

ANDRADE, R.R., Modelagem cinética do processo de produção de etanol a partir de Hidrolisado enzimático de bagaço de cana-de-açúcar concentrado com melaço considerando reciclo de células. Tese (Doutorado em Engenharia Química). Universidade Estadual de Campinas, 2012.

BRAGA, A. P.; CARVALHO, A. P. L.; LUDERMIR, T. B. Redes neurais artificiais: teoria e aplicações. Rio de Janeiro: LTC, 2000.

FONSECA, A.P.; OLIVEIRA, J.V.; LIMA, E.L. Neural Networks for Predicting Mass Transfer Parameters in Supercritical Extraction. Braz. J. Chem. Eng., v.17 n.4-7 São Paulo, 2000.

GUERRA, J.L., GARCIA, V.F.; Modelagem matemática de fermentação alcoólica com reciclo de células, Universidade Federal de São paulo, Graduação em Engenharia Química, 2015.

RAMOS, J. P. S.; Redes neurais artificiais na classificação de frutos: cenário bidimensional. Ciênc. agrotec. vol.27 no.2, 2003.

VALDEZ-CASTRO, L.; BARUCH, I., BARRERA-CORTE'S, J. Neural networks applied to the prediction of fed-batch fermentation kinetics of Bacillus thuringiensis. Bioprocess Biosyst Eng 25, p. 229-233, 2003. 